Article

\title{
Equivalent Modeling of Dfig-Based Wind Farms for Sub-Synchronous Resonance Analysis
}

\author{
Gangui Yan, Dan Wang, Qi Jia * and Wenbo Hu \\ Ministry of Education Key Laboratory of Modern Power System Simulation Control and Green \\ Power Technology, Northeast Electric Power University, Jilin 132012, China; yangg@neepu.edu.cn (G.Y.); \\ 1201600005@neepu.edu.cn (D.W.); 2201800136@neepu.edu.cn (W.H.) \\ * Correspondence: 2201800207@neepu.edu.cn; Tel.: +86-159-4869-2960
}

Received: 23 September 2020; Accepted: 14 October 2020; Published: 17 October 2020

\begin{abstract}
The order of the detailed model of doubly-fed induction generator (DFIG) wind farms are too high and the simulation is difficult. Most of the existing research has used a single-machine equivalent model and clustering aggregation model for equivalence and few papers have explored the principles and equivalent conditions of the single-machine equivalent model under sub-synchronous resonance (SSR). Due to this reason, this paper equates DFIG wind farms connected with series compensated transmission network to two separate units based on the principle of matrix similarity transformation and the mathematical model and physical model of each unit has been studied. Then, the DFIG wind farm equivalent model's validity is analyzed in number difference and collecting line difference based on linearization analysis. Finally, the system model is built in EMTDC/PSCAD, the damping analysis method is used to test the equivalent model's validity and further reveal the mechanism of the system's unstable operation. The results show that: the equivalent model can effectively reduce the system dimension and accurately reflect the dominant oscillation characteristics of DFIG wind farm under SSR; when SSR occurs, the damping coefficient of DFIG wind farm is negative under the oscillation frequency.
\end{abstract}

Keywords: DFIG wind farm; SSR; equivalent model; similarity transformation

\section{Introduction}

Large-scale development and utilization of wind energy is an important part of China's energy strategy. By the end of 2019, the cumulative installed capacity of wind power in China has reached 210 million $\mathrm{kW}$. It is estimated that wind power's installed capacity in China will reach 2.4 billion $\mathrm{kW}$ by 2050 [1]. Most of the wind farms are far away from the load center. Thus the series compensation technology has been widely used in large-capacity and long-distance transmission of wind power; however, there is a risk of sub-synchronous resonance (SSR) [2-4].

Several SSR accidents have occurred recently. In October 2009, the doubly-fed induction generator (DFIG) wind farms in Texas, U.S., were radially connected with series compensation line, which caused many wind turbines to out of the grid and their protection circuits damaged [5]. In 2012, it experienced multiple SSR caused by DFIG wind farms and compensated lines in Guyuan, China, resulting in many wind turbines out of the grid. The oscillation frequency was 3-8 Hz [6].

Aiming at SSR between DFIG wind farms connected with a series compensated transmission network, global researchers analyze the generation mechanism and influencing factors by eigenvalue analysis, impedance analysis and time-domain simulation and so forth. The research results show that: the SSR mechanism of DFIG wind farm connected with the series compensated transmission network is an induction generator effect (IGE) related to the control system [7-9]. When the oscillation occurs, the equivalent resistance of DFIG wind farm becomes negative at the resonant frequency, when the 
absolute value of negative resistance exceeds the grid resistance, the current will continue to exist and increase and the system is unstable at sub-synchronous frequency.

In Reference [10], the impedance equivalent model in DFIG-based series compensated system was derived, the Nyquist criterion was used to verify the mechanism, at the same time, it concluded that SSR had nothing to do with torsional interaction (TI) in this condition. Based on the actual oscillation data in Guyuan, Reference [11] verified the negative resistance effect of DFIG by conducting impedance modeling of DFIG and permanent magnetic synchronous generator (PMSG). In addition, it studied that control parameters greatly increased the negative resistance at the oscillation frequency, which was the main reason for the self-excited SSR in low series compensation degrees. Based on impedance model, positive net damping analysis and open-loop modal resonance analysis, DFIG wind farm was modeled in Reference [12], it was studied that both negative resistance and negative net damping were closely related to the strong dynamic interactions between DFIG wind farms and grid. Based on the frequency domain modal analysis method, the impedance model was used to determine that when SSR oscillated in Guyuan area, the sub-synchronous current flowed along the oscillation path constituted by series-compensated lines and DFIG turbines [13].

The main influencing factors of stability in DFIG-based series compensated system are wind speed, series compensation degrees, a number of DFIG turbines and the proportional coefficient $k_{\mathrm{P}}$ in the inner ring of the rotor side converter $[14,15]$. Among them, the wind speed, series compensation degrees and $k_{\mathrm{P}}$ have a linear relationship with the system stability: the higher the wind speed, the smaller the series compensation degrees and $k_{\mathrm{P}}$, the stronger the system stability; the number of DFIG turbines has a nonlinear relationship with the system stability. Moreover, DFIG turbines at different positions have different effects on SSR resonance characteristics [16].

The above research of DFIG wind farm is based on the single-machine multiplication model. Due to a large number of wind turbines, the detailed model dimension is too high and the simulation is difficult. Thus, most of the existing research use an equivalent model to represent DFIG wind farm. The common equivalent modeling methods are the single-machine equivalent multiplication method and the clustering aggregation method [17-19]. The single-machine multiplication equivalence method usually takes the equivalent wind speed of DFIG wind farm as the input wind speed of a single DFIG turbine and uses the weighted equivalence method to calculate all wind turbine parameters. The clustering aggregation method is used to cluster DFIG turbines according to certain indexes, then each group can be equivalent to a single-machine. $[20,21]$ proposed a method for evaluating the accuracy of the equivalent model of wind turbines and evaluated two equivalent models' accuracy under steady-state, sudden wind speed and fault conditions. Most of the existing research has focused on the power angle stability of the equivalent model under disturbance, while few papers focus on the mechanism and identical conditions of the single-machine multiplication model of DFIG wind farm under SSR.

The following is the core contributions of this paper:

- Based on the matrix similarity transformation theory, DFIG wind farm connected with series compensated transmission network can be equivalent to two separate units and the corresponding physical model and oscillation mode of two separate units are given. The theoretical analysis shows that: when the DFIG turbines have same characteristic parameters, load characteristics and the structure is symmetrical, the equivalent model can accurately describe the DFIG wind farm's oscillation modes.

- Through the eigenvalue analysis method, the validity of the DFIG wind farm's equivalent model was verified by considering the differences in operating conditions, the number of DFIG turbines and collecting lines. At the same time, other influencing factors are studied, the applicability of the equivalent model to super-synchronous oscillation is also briefly analyzed.

- Based on the damping analysis method, the sub-synchronous oscillation mechanism of DFIG wind farm connected with the series compensated transmission network is further revealed. 
The rest of this paper is organized as follows. Section 2 gives the structure of the DFIG wind farm connected with series compensated transmission network. Section 3 describes the modeling method of DFIG turbines. In Section 4 , the equivalent models of 2-machine system, $n$-machine system and DFIG wind farm are extended in detail. Section 5 verifies the effectiveness of DFIG wind farm equivalent model. Section 6 further analyzes the mechanism under SSR in DFIG-based series compensated system. Section 7 gives a conclusion.

\section{Structure of DFIG Wind Farm Connected with Series Compensated Transmission Network}

The structure of DFIG wind farm connected with the series compensated transmission network is shown in Figure 1. At first, the DFIG wind farm (multiple DFIG turbines with a capacity of $1.5 \mathrm{MW}$ ) is stepped up by a transformer and connected to the point of common coupling (PCC) in a radial manner, then stepped up again by the transformer and finally connected to the $500 \mathrm{kV}$ system through a compensated transmission. In Figure $1, R_{\mathrm{g}}, L_{\mathrm{g}}$ and $C_{\mathrm{g}}$ are the resistance, inductance and series compensation capacitor of the transmission line respectively, $L_{c}$ is the inductance between the DFIG turbines and PCC.

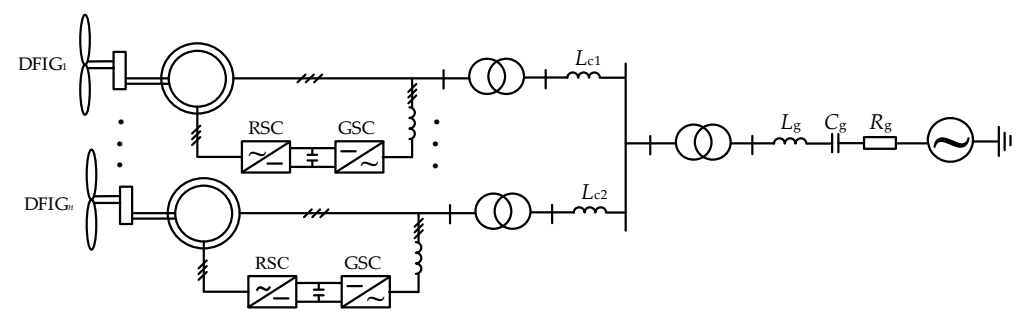

Figure 1. Structure of doubly-fed induction generator (DFIG) wind farm connected with the series compensated transmission network.

\section{Modeling of DFIG}

\subsection{Mathematical Model of DFIG Turbine}

The DFIG consists of the wind turbine, asynchronous induction motor, connection inductor of the converter, rotor side converter (RSC), grid side converter (GSC) and control system. Using the idea of a blocking model, each part of DFIG turbine is modeled as follows, separately. The List of notations is shown in Table A1 in Appendix A.

The induction generator's stator and rotor windings adopt the motor convention and establish in $d q$ axis, in which the $q$ axis leads the $d$ axis by $90^{\circ}$ [22], where the state variables are flux linkage of stator $\psi_{\mathrm{sd}}, \psi_{\mathrm{sq}}$, and flux linkage of rotor $\psi_{\mathrm{rd}}, \psi_{\mathrm{rq}}$ respectively.

The participation factors analysis in paper [7] shows that the SSR of DFIG is independent to the torsional mass block. Therefore, the internal difference of torsional can be ignored and a one-mass can be established, where the state variable is the rotor speed $\omega_{\mathrm{r}}$.

The impedance of the RSC connection circuit can be incorporated into the impedance of the rotor winding. Thus only the GSC connection circuit is modeled, where the state variables are GSC output current $i_{\mathrm{cgd}}, i_{\mathrm{cgq}}$ and dc-link capacitor voltage $u_{\mathrm{dc}}$.

The control system adopts the decoupling control in $d q$ axis based on the terminal voltage vector orientation, in which RSC adjusts the rotor speed according to the actual wind speed and keeps the reactive power output of the generator to 0 . The control strategy of RSC is shown in Figure 2a. 


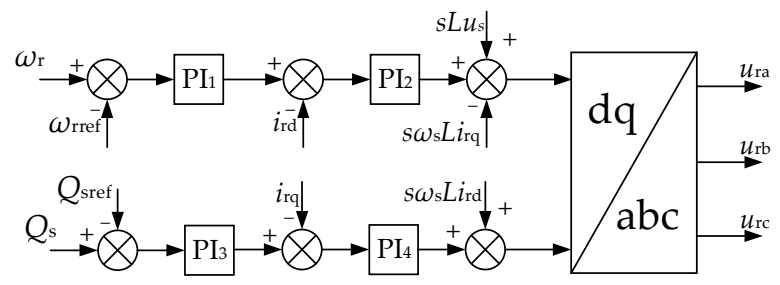

(a)

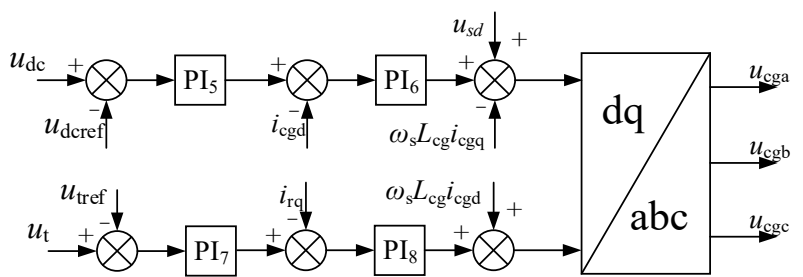

(b)

Figure 2. Structure diagram of control system (a) Control strategy of rotor side converter (RSC);

(b) Control strategy of grid side converter (GSC).

Where $\omega_{\mathrm{r}}$ and $\omega_{\text {rref }}$ are the actual and reference value of rotor speed, respectively; $Q_{\mathrm{s}}$ and $Q_{\text {sref }}$ are the actual and reference value of the stator reactive power, respectively; $L$ is the coupling inductance; $u_{\mathrm{r}}$ and $i_{\mathrm{r}}$ are the output voltage and current of RSC, respectively.

GSC regulates the dc-link voltage stability and maintains the terminal voltage constant in a dynamic process. The control strategy of GSC is shown in Figure $2 \mathrm{~b}$. Where $u_{\mathrm{dc}}$ and $u_{\mathrm{dcref}}$ are the actual and reference value of voltage in dc-link, respectively; $u_{\mathrm{t}}$ and $u_{\text {tref }}$ are the actual and reference voltage of PCC, respectively; $L_{\mathrm{cg}}$ is the GSC connection inductance; $u_{\mathrm{cg}}$ and $i_{\mathrm{cg}}$ are the output voltage and current of GSC, respectively.

Each part is modeled in blocks and then connected according to the input and output relationship.

\subsection{Mathematical Model of Grid}

DFIG is connected to the grid through the ground capacitor and series compensation line, where the state variables are the ground capacitance voltage $u_{\mathrm{cd}}, u_{\mathrm{cq}}$, the series compensation capacitance voltage $u_{\mathrm{cssd}}, u_{\mathrm{cssq}}$ and the line current $i_{\mathrm{gd}}, i_{\mathrm{gq}}$.

\subsection{Linear Model}

Based on the mathematical models in 3.1, the linearization model of DFIG turbine with 16 orders can be described by:

$$
\left\{\begin{aligned}
\dot{X}_{U} & =A_{1} X_{U}+B_{1} U_{U} \\
Y_{U} & =C_{1} X_{U}
\end{aligned}\right.
$$

- $\quad$ state variables $X_{\mathrm{U}}=\left[\Delta \omega_{\mathrm{r}}, \Delta \psi_{\mathrm{sd}}, \Delta \psi_{\mathrm{sq}}, \Delta \psi_{\mathrm{rd}}, \Delta \psi_{\mathrm{rq}}, \Delta i_{\mathrm{cgd}}, \Delta i_{\mathrm{cgq}}, \Delta u_{\mathrm{dc}}, \Delta x_{1} \sim \Delta x_{8}\right]$ and $X_{\mathrm{U}}$ is $16 \times 1$ matrix.

- $\quad$ input $U_{\mathrm{U}}=\left[\Delta T_{\mathrm{m}}, \Delta Q_{\text {ref }}, \Delta \omega_{\text {rref }}, \Delta u_{\mathrm{dcref}}, \Delta u_{\mathrm{sd}}, \Delta u_{\mathrm{sq}}\right]$ and input $U_{\mathrm{U}}$ is $6 \times 1$ matrix.

- output $Y_{\mathrm{U}}=\left[\Delta i_{\mathrm{cgd}}, \Delta i_{\mathrm{cgq}}, \Delta i_{\mathrm{sd}}, \Delta i_{\mathrm{sq}}\right]$ and output $Y_{\mathrm{U}}$ is $4 \times 1$ matrix.

The linearization model of power grid with 6 orders can be described by:

$$
\left\{\begin{aligned}
\dot{X}_{\mathrm{L}} & =\mathrm{A}_{2} X_{\mathrm{L}}+\mathrm{B}_{2} U_{\mathrm{L}} \\
Y_{\mathrm{L}} & =\mathrm{C}_{2} X_{\mathrm{L}}
\end{aligned}\right.
$$

- $\quad$ state variables $X_{\mathrm{L}}=\left[\Delta u_{\mathrm{pcd}}, \Delta u_{\mathrm{pcq}}, \Delta u_{\mathrm{cssd}}, \Delta u_{\mathrm{cssq}}, \Delta i_{\mathrm{gd}}, \Delta i_{\mathrm{gq}}\right]$ and $X_{\mathrm{L}}$ is $16 \times 1$ matrix.

- input $U_{\mathrm{L}}=\left[\Delta i_{\mathrm{cgd}}, \Delta i_{\mathrm{cgq}}, \Delta i_{\mathrm{sd}}, \Delta i_{\mathrm{sq}}\right]$ and input $U_{\mathrm{L}}$ is $4 \times 1$ matrix. 
- $\quad$ output $Y_{\mathrm{L}}=\left[\Delta u_{\mathrm{sd}}, \Delta u_{\mathrm{sq}}\right]$ and output $Y_{1}$ is $2 \times 1$ matrix.

The interface relationship between DFIG and power grid is shown in Figure 3, where DFIG turbine outputs current to the grid and the grid outputs voltage to DFIG turbine, which constitutes a closed loop system.

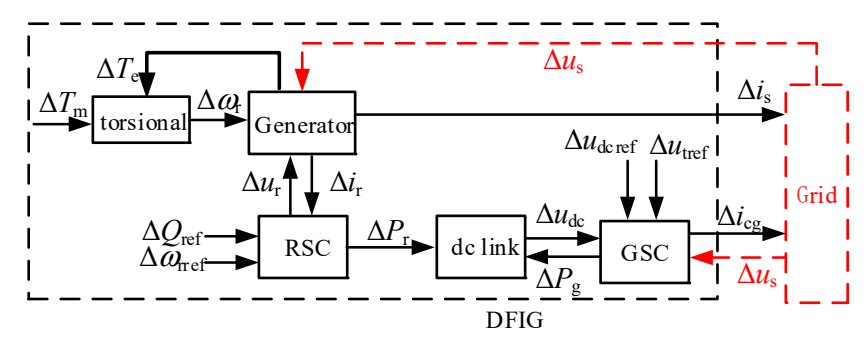

Figure 3. The interface relationship between DFIG turbine and grid.

The DFIG turbine and grid system can be simplified as:

$$
\begin{aligned}
& \dot{X}_{\mathrm{U}}=\mathrm{A}_{1} X_{\mathrm{U}}+\mathrm{B}_{1}\left[\begin{array}{c}
\Delta u_{\mathrm{sd}} \\
\Delta u_{\mathrm{sq}}
\end{array}\right]=\mathrm{A}_{\mathrm{U}} X_{\mathrm{U}}+\mathrm{B}_{\mathrm{U}} X_{\mathrm{L}} \\
& \dot{X}_{\mathrm{L}}=\mathrm{A}_{2} X_{\mathrm{L}}+\mathrm{B}_{2}\left[\begin{array}{c}
\Delta i_{\mathrm{cgd}} \\
\Delta i_{\mathrm{cgq}} \\
\Delta i_{\mathrm{sd}} \\
\Delta i_{\mathrm{sq}}
\end{array}\right]=\mathrm{A}_{\mathrm{L}} X_{\mathrm{L}}+\mathrm{B}_{\mathrm{I}} X_{\mathrm{U}}
\end{aligned}
$$

where $A_{U}$ and $A_{L}$ represent the coupling relationship between internal variables of DFIG and grid, $B_{U}$ and $B_{I}$ represent the interface relationship of voltage and current between DFIG and grid respectively. The List of matrices notations is shown in Table A2 in Appendix A.

\section{Modeling of DFIG Wind Farm}

\subsection{Equivalent Model of the Two-Machine System}

The basic principle of the equivalent model is derived by taking two parallel DFIG turbines connected with series compensated transmission network, in which two DFIG turbines are of the same type, with symmetrical structure, same parameters and load characteristics. The system consists of 3 parts [23]: turbine1, turbine2 of DFIG and grid. The dynamics of each part are given by:

$$
\begin{gathered}
\dot{X}_{\mathrm{U} 1}=\mathrm{A}_{\mathrm{U}} X_{\mathrm{U} 1}+\mathrm{B}_{\mathrm{U}} X_{\mathrm{L}} \\
\dot{X}_{\mathrm{U} 2}=\mathrm{A}_{\mathrm{U}} X_{\mathrm{U} 2}+\mathrm{B}_{\mathrm{U}} X_{\mathrm{L}} \\
\dot{X}_{\mathrm{L}}=\mathrm{A}_{\mathrm{L}} X_{\mathrm{L}}+\mathrm{B}_{\mathrm{I}} X_{\mathrm{U} 1}+\mathrm{B}_{\mathrm{I}} X_{\mathrm{U} 2}
\end{gathered}
$$

where state variables subscript 1,2 represents turbine1, turbine2 of DFIG turbine.

The closed-loop system can be described by:

$$
\left[\begin{array}{c}
\dot{X}_{\mathrm{U} 1} \\
\dot{X}_{\mathrm{U} 2} \\
\dot{X}_{\mathrm{L}}
\end{array}\right]=\left[\begin{array}{ccc}
\mathrm{A}_{\mathrm{U}} & 0 & \mathrm{~B}_{\mathrm{U}} \\
0 & \mathrm{~A}_{\mathrm{U}} & \mathrm{B}_{\mathrm{U}} \\
\mathrm{B}_{\mathrm{I}} & \mathrm{B}_{\mathrm{I}} & \mathrm{A}_{\mathrm{L}}
\end{array}\right]\left[\begin{array}{c}
\mathrm{X}_{\mathrm{U} 1} \\
X_{\mathrm{U} 2} \\
X_{\mathrm{L}}
\end{array}\right]=\mathrm{A}\left[\begin{array}{c}
\mathrm{X}_{\mathrm{U} 1} \\
X_{\mathrm{U} 2} \\
X_{\mathrm{L}}
\end{array}\right] .
$$


Based on the similarity transformation theorem that the original matrix and similar matrix have the same eigenvalue, the system state matrix A can be similarly transformed. One of the similar transformation matrix $\mathrm{P}$ is:

$$
\mathrm{P}=\left[\begin{array}{ccc}
0.5 \mathrm{I}_{\mathrm{U}} & \mathrm{I}_{\mathrm{U}} & 0 \\
-0.5 \mathrm{I}_{\mathrm{U}} & \mathrm{I}_{\mathrm{U}} & 0 \\
0 & 0 & \mathrm{I}_{\mathrm{L}}
\end{array}\right]
$$

where $\mathrm{I}_{\mathrm{U}}$ is a $16 \times 16$ unit matrix, $\mathrm{I}_{\mathrm{L}}$ is a $6 \times 6$ unit matrix. The state matrix $\mathrm{A}$ can be diagonalized as $\mathrm{B}$ :

$$
\mathrm{B}=\mathrm{P}^{-1} \mathrm{AP}=\left[\begin{array}{ccc}
\mathrm{A}_{U} & 0 & 0 \\
0 & \mathrm{~A}_{U} & \mathrm{~B}_{U} \\
0 & 2 \mathrm{~B}_{\mathrm{I}} & \mathrm{A}_{\mathrm{L}}
\end{array}\right]
$$

The similarity matrix $\mathrm{B}$ is a block diagonal matrix, in which the eigenvalues are the set of two sub-matrices $A_{U}$ and $\left[A_{U}, B_{U} ; 2 B_{I}, A_{L}\right]$, then the eigenvalues of the system state matrix $A$ can be characterized by two sub-matrices.

There is no relationship between the eigenvalues of two sub-matrices, which correspond to two separate units. The first part $A_{U}$ can be called single-machine to infinite bus system, which is equivalent to one DFIG turbine directly connected to an infinite bus. The second part $\left[\mathrm{A}_{\mathrm{U}}, \mathrm{B}_{\mathrm{U}} ; 2 \mathrm{~B}_{\mathrm{I}}, \mathrm{A}_{\mathrm{L}}\right]$ can be called modified single-machine to the grid, which is equivalent to the current component $B_{I}$ in the grid interface of a single DFIG turbine multiplied by coefficient 2 and then connected to the infinite system through the original transmission line.

Since the similarity transformation matrix $\mathrm{P}$ is not unique, countless similarity transformation matrices can be constructed for the system state matrix A. Further analysis shows that the similarity transformation matrix of matrix A satisfies condition:

- $\quad$ sub-matrix $\mathrm{A}_{\mathrm{U}}$ has not changed.

- sub-matrix $\left[\mathrm{A}_{\mathrm{U}}, k_{1} \mathrm{~B}_{\mathrm{U}} ; k_{2} \mathrm{~B}_{\mathrm{I}}, \mathrm{A}_{\mathrm{L}}\right]$ satisfies the product of the coefficient $k_{1}$ and $k_{2}$ of the current component $\mathrm{B}_{\mathrm{U}}$ and voltage component $\mathrm{B}_{\mathrm{I}}$ is 2 .

Therefore, the two-machine system can be equivalent, as shown in Figure 4. Among them, single-machine to the infinite bus can reflect the oscillation modes in DFIG turbines, while the modified single-machine to the grid can reflect the oscillation modes between DFIG turbines and the grid. Since it is always stable to single-machine to the infinite bus, the system's stability under SSR only depends on the single-machine to grid.

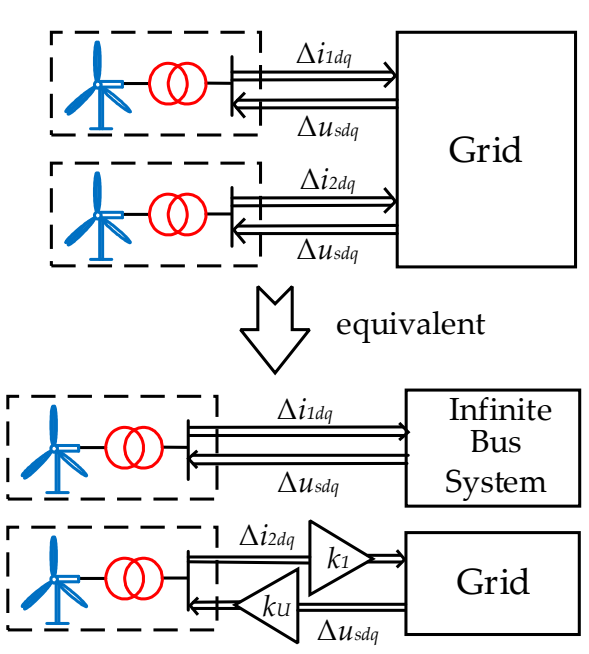

Figure 4. Equivalent model of two parallel DFIG turbines connected with series compensated transmission network. 


\subsection{Equivalent Model of the N-Machine System}

When $n(n>2)$ parallel DFIG turbines connected with series compensated transmission network, the equivalent model can be constructed based on the same method. Among them, DFIG turbines are of the same type, in which $n$ parallel DFIG turbines are in the same type, with symmetrical structure, same parameters and load characteristics. The $n$-machine system state matrix $\mathrm{A}_{\mathrm{N}}$ is as follows:

$$
\mathrm{A}_{\mathrm{N}}=\left[\begin{array}{ccccc}
\mathrm{A}_{\mathrm{U}} & 0 & \cdots & 0 & \mathrm{~B}_{\mathrm{U}} \\
0 & \ddots & & \vdots & \vdots \\
\vdots & & \ddots & 0 & \vdots \\
0 & \cdots & 0 & \mathrm{~A}_{\mathrm{U}} & \mathrm{B}_{\mathrm{U}} \\
\mathrm{B}_{\mathrm{I}} & \cdots & \cdots & \mathrm{B}_{\mathrm{I}} & \mathrm{B}_{\mathrm{U}}
\end{array}\right]
$$

Based on the similarity transformation theorem, matrix $\mathrm{A}_{\mathrm{N}}$ can be similarly transformed as:

$$
\mathrm{P}_{\mathrm{N}}{ }^{-1} \mathrm{~A}_{\mathrm{N}} \mathrm{P}_{\mathrm{N}}=\left[\begin{array}{ccccc}
\mathrm{A}_{\mathrm{U}} & 0 & \cdots & 0 & 0 \\
0 & \ddots & & \vdots & \vdots \\
\vdots & & \ddots & 0 & \vdots \\
0 & \cdots & 0 & \mathrm{~A}_{\mathrm{U}} & k_{1} \mathrm{~B}_{\mathrm{U}} \\
0 & \cdots & \cdots & k_{2} \mathrm{~B}_{\mathrm{I}} & \mathrm{B}_{\mathrm{U}}
\end{array}\right]
$$

The eigenvalues of $n$-machine system state matrix $\mathrm{A}_{\mathrm{N}}$ can be composed of two parts. The first part diag $\left[A_{U}, \ldots, A_{U}\right]$ can be equivalent to single DFIG turbine to infinite bus (the multiplier is $n-1)$, reflecting the oscillation modes in DFIG turbines. The second part $\left[\mathrm{A}_{\mathrm{U}}, k_{1} \mathrm{~B}_{\mathrm{U}} ; k_{2} \mathrm{~B}_{\mathrm{I}}, \mathrm{A}_{\mathrm{L}}\right]$ can be equivalent to a modified single DFIG turbine to grid with the product of the coefficient $k_{1}$ and $k_{2}$ of the current component $B_{U}$ and voltage component $B_{I}$ is $n$, which reflects the oscillation modes between DFIG turbines and grid.

When the DFIG turbines are of the same type, that is, in the same type, with symmetrical structure, same parameters and load characteristics. The equivalent model greatly reduces the system dimension; after equivalence, the system order is reduced from $16 \times n+6$ to 16 (single DFIG turbine to the infinite bus) +22 order (modified single DFIG turbine to the grid).

\subsection{Equivalent Model of DFIG Wwind Farm}

DFIG wind farm consists of hundreds of wind turbines generally. DFIG turbines are difficult to under the same operating conditions due to different position and influence of the wake effect, which cannot meet the equivalent conditions. At this point, DFIG wind farm can be divided into several groups composed of DFIG turbines with similar operating conditions. Hence each group's DFIG turbines are approximately equivalent to the same operating conditions, each group can be equivalent to two separate units; otherwise, different groups cannot be equivalent. The equivalent model of DFIG wind farm is shown in Figure 5. 


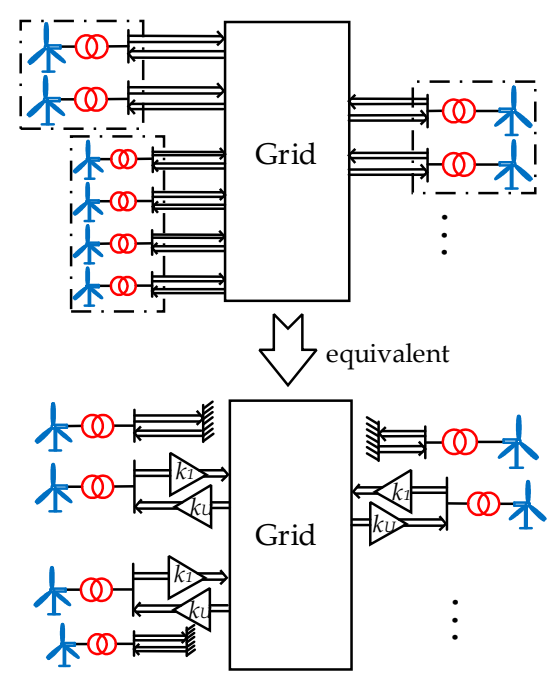

Figure 5. Equivalent model of parallel DFIG wind farm connected with series compensated transmission network.

\subsection{Wind Farm Equivalence Model Verification}

To verify the accuracy of the theoretical analysis, a linearized model of a DFIG wind farm connected with series compensated transmission network as shown in Figure 6 has built, in which DFIG wind farm is characterized by 20 parallel DFIG turbines (the multiplier of each turbine is 100). The $24 \mathrm{~h}$ actual wind speed data of 20 wind turbines in a Jilin wind farm is shown in Figure 7 (the sampling interval is $15 \mathrm{~min}$ ). The actual wind speed data at a certain time $t_{1}$ is selected as the input wind speed of DFIG wind farm, as shown in Table A3 in Appendix B.

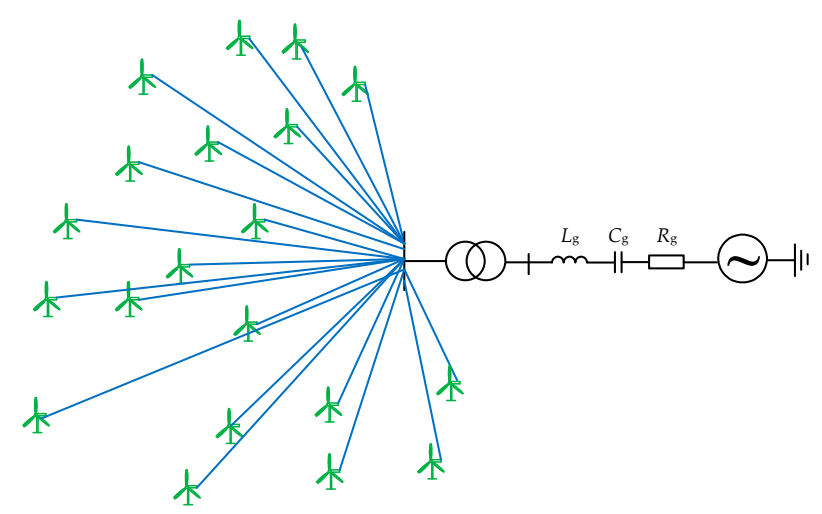

Figure 6. Model of a 20 parallel DFIG turbines connected with series compensated transmission network.

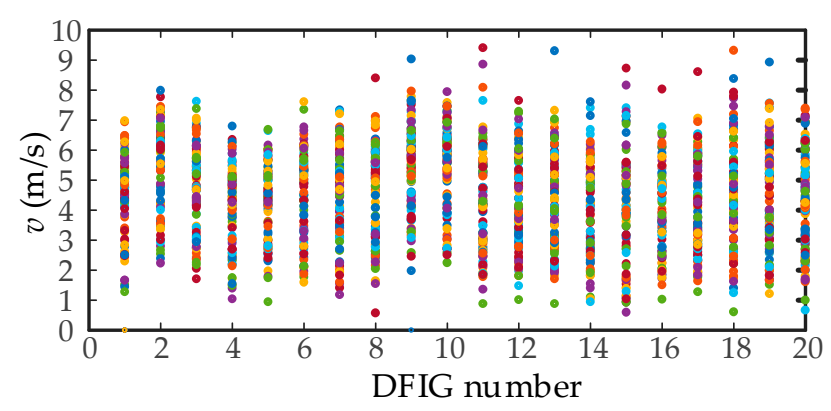

Figure 7. $24 \mathrm{~h}$ actual wind speed data of 20 wind turbines (the sampling interval is $15 \mathrm{~min}$ ).

The time domain simulation model and linearized model of detailed DFIG wind farm is constructed, in which the same parameters and operating points are adopted. By setting the DC voltage reference 
disturbance ( $t=15 \mathrm{~s}, 0.1$ p.u. voltage step change is applied; $t=20 \mathrm{~s},-0.1$ p.u. voltage step change is applied), the matching degree of the results of the two models is compared in Figure 8 to verify the effectiveness of the model.

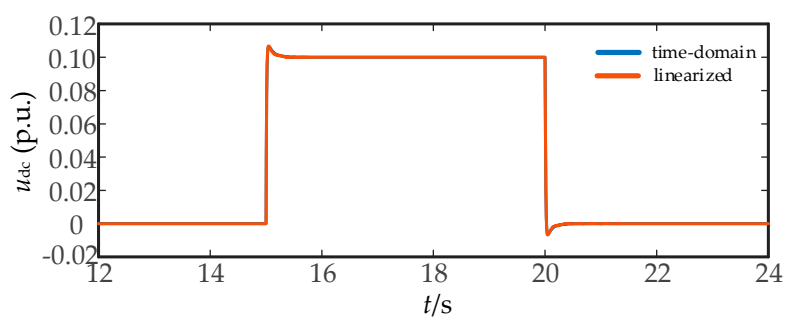

(a)

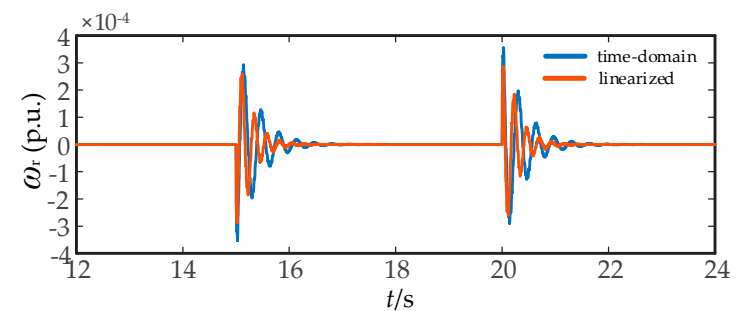

(b)

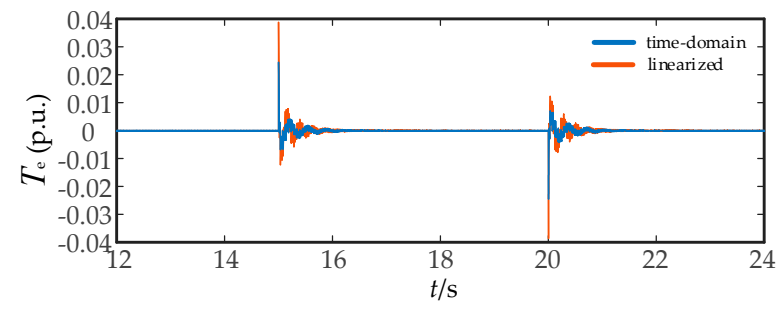

(c)

Figure 8. Model validation (a) DC voltage $u_{\mathrm{dc}} ;(\mathbf{b})$ speed $\omega_{\mathrm{r}} ;(\mathbf{c})$ electromagnetic torque $T_{\mathrm{e}}$.

It can be seen from Figure 8 that after the step disturbance, the time-domain simulation model and the linearized model have the same fluctuation trend of DC voltage $u_{\mathrm{dc}}$, while the fluctuation amplitude and phase angle of the rotational speed $\omega_{\mathrm{r}}$ and the electromagnetic torque $T_{\mathrm{e}}$ are slightly different but the fluctuation trend is roughly the same.

Based on the $k$-means grouping algorithm [24], determine the number of groups $k=4$, the 20 DFIG turbines is divided into 4 groups. The results are shown in Table 1.

Table 1. The results of grouping.

\begin{tabular}{cccc}
\hline Groups & Operating Condition $(\mathbf{m} / \mathbf{s})$ & Groups & Operating Condition $(\mathbf{m} / \mathbf{s})$ \\
\hline Group 1 & 3.466 & & 5.118 \\
& 3.625 & & 5.133 \\
3.756 & Group 3 & 5.205 \\
& 3.770 & & 5.655 \\
& 3.843 & & 5.669 \\
& 4.046 & & 5.923 \\
& 4.133 & Group 4 & 6.249 \\
& 4.292 & & 6.655 \\
Group 2 & 4.625 & & 6.742 \\
& 5.082 & & 6.923 \\
\hline
\end{tabular}


Construct a linearized model of the equivalent system and verify the equivalent model's accuracy, when RSC current inner loop control parameters $k_{\mathrm{P}}=0.01$ p.u., the partial eigenvalues of the detailed model and equivalent model are shown in Tables $2-4$.

According to Tables $2-4$, when $k_{\mathrm{P}}=0.01$ p.u., the system is stable, the error rate of the real part of the eigenvalues by the equivalent model is less than $2.7 \%$ and that of the imaginary part is less than $1.5 \%$, in which the real part error rate of dominant oscillation eigenvalues is $0.68 \%$ and there is no error in the imaginary part.

Table 2. The partial eigenvalues of the detailed model.

\begin{tabular}{cccc}
\hline Eigenvalues & Frequency & Eigenvalues & Frequency \\
\hline-5020 & 0 & -11.8 & 0 \\
-4740 & 0 & -11 & 0 \\
-4620 & 0 & $-8.75 \pm \mathrm{j} 23.5$ & 3.74 \\
-4530 & 0 & $-1.9 \pm \mathrm{j} 313$ & 49.84 \\
$-4060 \pm \mathrm{j} 17,500$ & 2786.62 & $-11.1 \pm \mathrm{j} 313$ & 49.84 \\
$-1590 \pm \mathrm{j} 15,900$ & 2531.85 & $-9.78 \pm \mathrm{j} 313$ & 49.84 \\
-111 & 0 & $-9.38 \pm \mathrm{j} 313$ & 49.84 \\
-95.9 & 0 & $-8.17 \pm \mathrm{j} 313$ & 49.84 \\
-30.6 & 0 & $-8.06 \pm \mathrm{j} 313$ & 49.84 \\
-29.4 & 0 & $-7.61 \pm \mathrm{j} 371$ & 59.08 \\
-28.6 & 0 & -4.33 & 0 \\
-27 & 0 & $-3.55 \pm \mathrm{j} 3.05$ & 0.49 \\
-26.5 & 0 & $-3.48 \pm \mathrm{j} 3.04$ & 0.48 \\
-20.1 & 0 & $-3.24 \pm \mathrm{j} 3.03$ & 0.48 \\
-20 & 0 & $-3.03 \pm \mathrm{j} 3.02$ & 0.47 \\
$-15.9 \pm \mathrm{j} 22.3$ & 3.55 & $-2.93 \pm \mathrm{j} 258$ & 41.08 \\
$-15.9 \pm \mathrm{j} 22.4$ & 3.57 & $-2.69 \pm \mathrm{j} 3.82$ & 0.61 \\
$-15.3 \pm \mathrm{j} 25.2$ & 4.01 & $-1.33 \pm \mathrm{j} 1.49$ & 0.24 \\
$-14.7 \pm \mathrm{j} 27.6$ & 4.39 & $-1.32 \pm \mathrm{j} 1.50$ & 0.24 \\
$-14.2 \pm \mathrm{j} 30.5$ & 4.86 & $-1.32 \pm \mathrm{j} 1.46$ & 0.23 \\
$-14 \pm \mathrm{j} 31.4$ & 5 & &
\end{tabular}

Table 3. The eigenvalues of the modified single-machine to the grid.

\begin{tabular}{cccc}
\hline Eigenvalues & Frequency & Eigenvalues & Frequency \\
\hline-5020 & 0 & $-14.9 \pm \mathrm{j} 25.1$ & 4.01 \\
-4740 & 0 & $-14.1 \pm \mathrm{j} 31.4$ & 5 \\
-4620 & 0 & -11.8 & 0 \\
-4530 & 0 & -11 & 0 \\
$-4060 \pm \mathrm{j} 17,500$ & 2786.62 & $-8.98 \pm \mathrm{j} 23.5$ & 3.74 \\
$-1590 \pm \mathrm{j} 15,900$ & 2531.85 & $-11.1 \pm \mathrm{j} 313$ & 49.84 \\
-111 & 0 & $-9.28 \pm \mathrm{j} 313$ & 49.84 \\
-95.7 & 0 & $-7.61 \pm \mathrm{j} 370$ & 58.92 \\
-30.6 & 0 & -4.35 & 0 \\
-29.3 & 0 & $-3.51 \pm \mathrm{j} 3.06$ & 0.49 \\
-27 & 0 & $-3.21 \pm \mathrm{j} 3.04$ & 0.48 \\
-26.3 & 0 & $-3.03 \pm \mathrm{j} 3.02$ & 0.47 \\
-20.1 & 0 & $-2.91 \pm \mathrm{j} 258$ & 41.08 \\
-20 & 0 & $-2.69 \pm \mathrm{j} 3.81$ & 0.61 \\
$-15.9 \pm \mathrm{j} 22.1$ & 3.52 & $-1.31 \pm \mathrm{j} 1.49$ & 0.24 \\
$-16 \pm \mathrm{j} 22.4$ & 3.57 & $-1.32 \pm \mathrm{j} 1.50$ & 0.24 \\
$-15.1 \pm \mathrm{j} 27.2$ & 4.33 & $-1.29 \pm \mathrm{j} 1.45$ & 0.23 \\
\hline
\end{tabular}


Table 4. The eigenvalues of the single-machine to an infinite bus.

\begin{tabular}{cccc}
\hline Eigenvalues & Frequency & Eigenvalues & Frequency \\
\hline-4740 & 0 & -11 & 0 \\
-4620 & 0 & $-9.83 \pm \mathrm{j} 313$ & 49.84 \\
-111 & 0 & $-8.11 \pm \mathrm{j} 313$ & 49.84 \\
-30.6 & 0 & $-8.09 \pm \mathrm{j} 313$ & 49.84 \\
-28.6 & 0 & $-3.49 \pm \mathrm{j} 3.04$ & 0.48 \\
-26.3 & 0 & $-3.24 \pm \mathrm{j} 3.03$ & 0.48 \\
-20.1 & 0 & $-3.03 \pm \mathrm{j} 3.02$ & 0.47 \\
-20 & 0 & $-3.03 \pm \mathrm{j} 3.02$ & 0.47 \\
$-16 \pm \mathrm{j} 22.6$ & 3.60 & $-1.32 \pm \mathrm{j} 1.50$ & 0.24 \\
$-15.9 \pm \mathrm{j} 22.1$ & 3.52 & $-1.31 \pm \mathrm{j} 1.47$ & 0.23 \\
$-15.1 \pm \mathrm{j} 27.1$ & 4.32 & $-1.31 \pm \mathrm{j} 1.49$ & 0.24 \\
$-14.2 \pm \mathrm{j} 32$ & 5.10 & $-1.29 \pm \mathrm{j} 1.45$ & 0.23 \\
$-11.7 \pm \mathrm{j} 313$ & 49.84 & &
\end{tabular}

To avoid the influence of chance on the accuracy of the equivalent model, when actual wind speed data at a certain time $t_{2}$ is selected as the input wind speed of DFIG wind farm, the input wind speed and grouping results are shown in Tables A4 and A5 in Appendix B. When RSC current inner loop control parameters $k_{\mathrm{P}}=0.01$ p.u., the partial eigenvalues of the detailed and equivalent models are shown in Table A6 in Appendix B. According to Table A6, when $k_{\mathrm{P}}=0.01$, the system is stable, the error rate of the real part of the eigenvalues by the equivalent model is less than $1.3 \%$ and that of imaginary part is less than $1.8 \%$, in which the real part error rate of dominant oscillation eigenvalues is $0.41 \%$ and there is no error in the imaginary part.

To sum up, under the two example conditions: the error rate of the real part of the equivalent model eigenvalues is less than $2.7 \%$ and that of the imaginary part is less than $1.8 \%$, in which the real part error rate of dominant oscillation eigenvalues is less than $0.68 \%$ and there is no error in imaginary part. Otherwise, the time-domain simulation time of the detailed model is $96 \mathrm{~min}$ and that of the equivalent model is $3 \mathrm{~min}$. The equivalent model simulation time is greatly shortened.

\section{Validity Analysis of the Equivalent Model}

When actual wind speed data at a certain time $t_{1}$ is selected as the input wind speed of DFIG wind farm, the validity of the equivalent model under SSR is analyzed when the number of DFIG turbines and the length of collecting lines are different. At the same time, other influencing factors, such as the RSC tie-reactor, on the accuracy of the equivalent model are also studied. In addition, the applicability of the equivalent model to super-synchronous oscillation is briefly analyzed.

The average Euclidean distance is introduced as the evaluation index:

$$
d=\frac{1}{n} \sum_{i=1}^{n} \sqrt{\left[\operatorname{Re}\left(\lambda_{\mathrm{e}}\right)-\operatorname{Re}\left(\lambda_{\mathrm{i}}\right)\right]^{2}+\left[\operatorname{Im}\left(\lambda_{\mathrm{e}}\right)-\operatorname{Im}\left(\lambda_{\mathrm{i}}\right)\right]^{2}}
$$

where $\lambda_{\mathrm{e}}$ and $\lambda_{\mathrm{i}}$ are the dominant oscillation eigenvalues of the equivalent model and the detailed model respectively; $n$ is the number of dominant oscillation eigenvalues. The smaller the average Euclidean distance, the more accurately the equivalent model can express the dominant oscillation characteristics.

\subsection{When the Difference in Collecting Lines and DFIG Turbines Number Is Not Considered}

Case 1: 20 DFIG turbines have the same number (the multiplier of each turbine is 100) and the collecting lines are not considered, the validity of the equivalent model under SSR is analyzed by changing the RSC current inner loop control parameter $k_{\mathrm{P}}$. When $k_{\mathrm{P}}$ is between 0.01 p.u. to 0.1 p.u., the results of dominant oscillation eigenvalues of the detailed model and equivalent model are shown in Figure 9. 


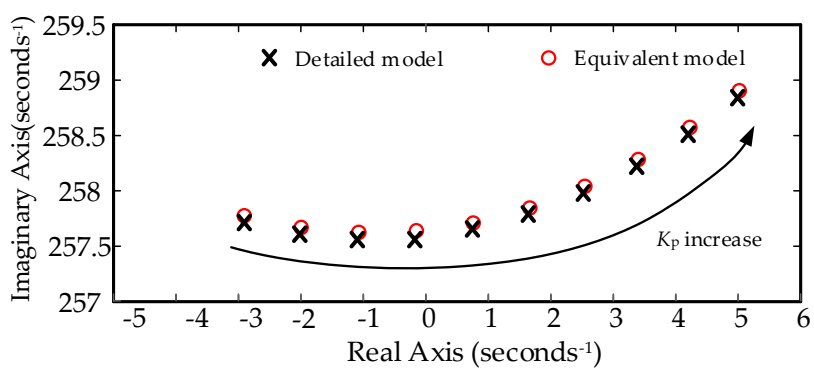

Figure 9. Results of dominant oscillation eigenvalues in case 1.

It can be seen from Figure 9 that when $k_{\mathrm{P}}$ changes from 0.01 p.u. to 0.1 p.u., the variation trend in equivalent model is the same as that in detailed model, in which the average Eucalyptus distance of the dominant eigenvalues is between 0.02 p.u. to 0.03 p.u. In this case, the equivalent model can accurately reflect the dominant oscillation characteristics of the DFIG wind farm and effectively reduce the dimension.

\subsection{When the Difference of DFIG Turbines Number Is Considered}

Case 2: Set the number of i-th wind turbines is $100+10(\mathrm{i}-1)$ and the collecting lines is not considered. When $\mathrm{k}_{\mathrm{P}}$ is between 0.01 p.u. to 0.1 p.u., the results of dominant oscillation eigenvalues of detailed model and equivalent model are shown in Figure 10.

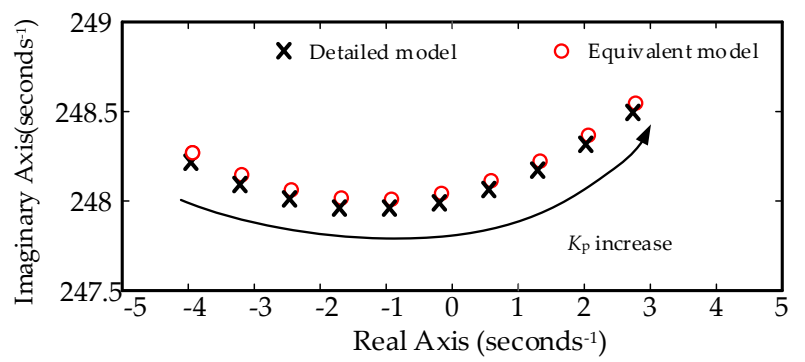

Figure 10. Results of dominant oscillation eigenvalues in case 2.

It can be seen from Figure 10 that when $k_{\mathrm{P}}$ changes from 0.01 p.u. to 0.1 p.u., the variation trend in equivalent model is the same as that in detailed model, in which the average Eucalyptus distance of the dominant eigenvalues is between 0.03 p.u. to 0.04 p.u., When considering the difference in the number of DFIG turbines, the accuracy of the dominant oscillation eigenvalues of the equivalent model is basically unchanged.

\subsection{When the Difference of Collecting Lines Is Considered}

Case 3: For the $i$-th DFIG turbine, the collecting line's length is set to be $0.5+0.01(i-1) \mathrm{km}$ and the number is the same (the multiplier of each turbine is 100). The equivalent model's collection line adopts the power loss equivalent method, that is, the original network is replaced with an equivalent impedance [25], so that the loss of the equivalent model output power at the equivalent impedance is equal to that of before the equivalent. The power loss on the collector network remains consistent. When $k_{\mathrm{P}}$ is between 0.01 p.u. to 0.1 p.u., the results of dominant oscillation eigenvalues of detailed model and equivalent model are shown in Figure 11. 


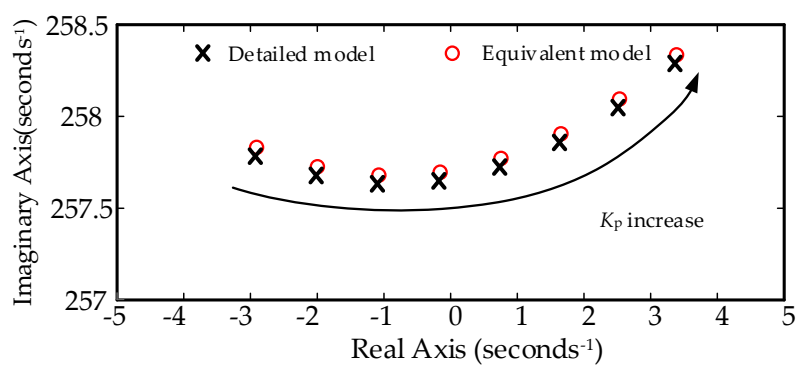

Figure 11. Results of dominant oscillation eigenvalues in case 3.

It can be seen from Figure 11 that when $k_{\mathrm{P}}$ changes from 0.01 p.u. to 0.1 p.u., the variation trend in equivalent model is the same as that in detailed model, in which the average Eucalyptus distance of the dominant eigenvalues is between 0.02 p.u. to 0.03 p.u. When considering the difference of the collecting lines, the accuracy of the dominant oscillation eigenvalues of the equivalent model is basically unchanged.

\subsection{Influence of RSC Connection Inductance}

According to Reference [26], the RSC tie-reactor may affect the oscillation characteristics of DFIG model. Based on the linearized model, the influence of RSC tie-reactor is studied. When RSC connecting inductance $L_{\mathrm{rsc}}$ changes, the eigenvalues of the detailed model and the equivalent model are as follows.

As can be seen from Table 5, with the change of $L_{\mathrm{rsc}}$, the eigenvalues of the detailed model and the equivalent model also change. Therefore, the value of RSC tie-reactor should be set as accurate as possible during modeling, so as to improve the accuracy of the model.

Table 5. The eigenvalues of detailed model and equivalent model when $L_{\mathrm{rsc}}$ changes.

\begin{tabular}{ccc}
\hline Change of $L_{\text {rsc }}$ & Detailed Model & Equivalent Model \\
\hline-0.03 p.u. & $-2.99 \pm \mathrm{j} 258$ & $-2.97 \pm \mathrm{j} 258$ \\
-0.02 p.u. & $-2.97 \pm \mathrm{j} 258$ & $-2.95 \pm \mathrm{j} 258$ \\
-0.01 p.u. & $-2.95 \pm \mathrm{j} 258$ & $-2.93 \pm \mathrm{j} 258$ \\
0 & $-2.93 \pm \mathrm{j} 258$ & $-2.91 \pm \mathrm{j} 258$ \\
0.01 p.u. & $-2.91 \pm \mathrm{j} 258$ & $-2.89 \pm \mathrm{j} 258$ \\
0.02 p.u. & $-2.90 \pm \mathrm{j} 258$ & $-2.87 \pm \mathrm{j} 258$ \\
0.03 p.u. & $-2.89 \pm \mathrm{j} 258$ & $-2.86 \pm \mathrm{j} 258$ \\
\hline
\end{tabular}

\subsection{Applicability of Equivalent Model for Super-Synchronous Oscillation}

According to the eigenvalues results of Tables 2-4 in Section 4.4, there is a pair of conjugate eigenvalues in super-synchronous range in the detailed model and the equivalent model. Set the proportional coefficient $k_{\mathrm{P}}$ in the inner ring of RSC from 0.01 p.u. to 0.1 p.u., the effect of the equivalent model on the super-synchronous oscillation is studied. The dominant eigenvalues of the super-synchronous oscillation are as follows.

It can be seen from Table 6 that the system's super-synchronous oscillation is not excited under the current case conditions. When $k_{\mathrm{P}}$ changes, the equivalent model can accurately reflect the change trend of the eigenvalues of the detailed model, the error rate of real part of eigenvalues by equivalent model is less than $0.11 \%$ and that of imaginary part is less than $0.77 \%$. 
Table 6. The eigenvalues of super-synchronous oscillation.

\begin{tabular}{ccccc}
\hline $\boldsymbol{K}_{\mathbf{p}}$ & Detailed Model & Frequency & Single-Machine to Infinite Bus System & Frequency \\
\hline 0.01 & $-7.61 \pm \mathrm{j} 371$ & 59.36 & $-7.61 \pm \mathrm{j} 370$ & 58.92 \\
0.02 & $-8.24 \pm \mathrm{j} 370$ & 58.92 & $-8.24 \pm \mathrm{j} 370$ & 58.92 \\
0.03 & $-8.86 \pm \mathrm{j} 370$ & 58.92 & $-8.87 \pm \mathrm{j} 370$ & 58.92 \\
0.04 & $-9.48 \pm \mathrm{j} 370$ & 58.92 & $-9.48 \pm \mathrm{j} 370$ & 58.92 \\
0.05 & $-10.1 \pm \mathrm{j} 370$ & 58.92 & $-10.1 \pm \mathrm{j} 370$ & 58.92 \\
0.06 & $-10.7 \pm \mathrm{j} 370$ & 58.92 & $-10.7 \pm \mathrm{j} 370$ & 58.92 \\
0.07 & $-11.3 \pm \mathrm{j} 369$ & 58.92 & $-11.3 \pm \mathrm{j} 369$ & 58.92 \\
0.08 & $-11.9 \pm \mathrm{j} 369$ & 58.76 & $-11.9 \pm \mathrm{j} 369$ & 58.76 \\
0.09 & $-12.4 \pm \mathrm{j} 369$ & 58.76 & $-12.4 \pm j 369$ & 58.76 \\
0.10 & $-13.0 \pm \mathrm{j} 368$ & 58.60 & $-13.0 \pm \mathrm{j} 368$ & 58.60 \\
\hline
\end{tabular}

\section{Damping Analysis}

The detailed model and equivalent model of DFIG wind farm connected with series compensated transmission network are built in EMTDC/PSCAD. The DFIG turbine parameter is shown in Table A7 in Appendix B and the series of compensation degrees of the system is $6.67 \%$. Based on the damping analysis method, the equivalent model's effectiveness is further verified and the oscillation mechanism is further revealed. The flowchart of online damping analysis is shown in Figure 12.

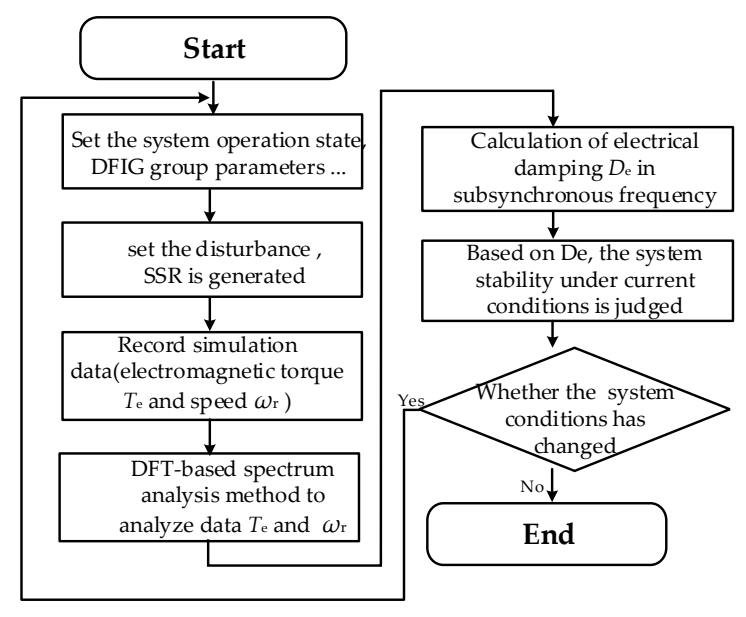

Figure 12. The flowchart of online damping analysis.

Under the conditions of case 1 and case 2, when it occurs to SSR, the electrical damping coefficient $D_{\mathrm{e}}$ and the inter-harmonic distribution in the electromagnetic torque of one of the DFIG turbines in the equivalent model are shown in Figures 13 and 14.

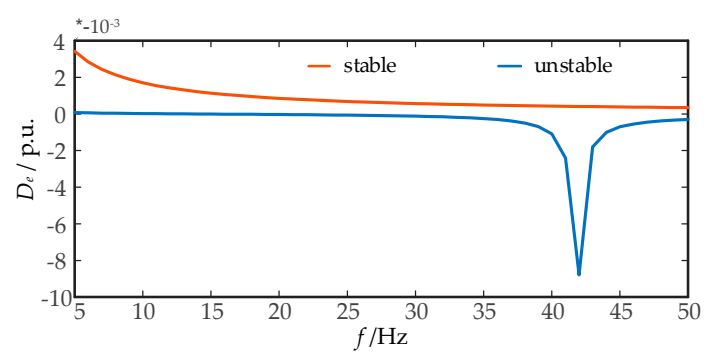

(a)

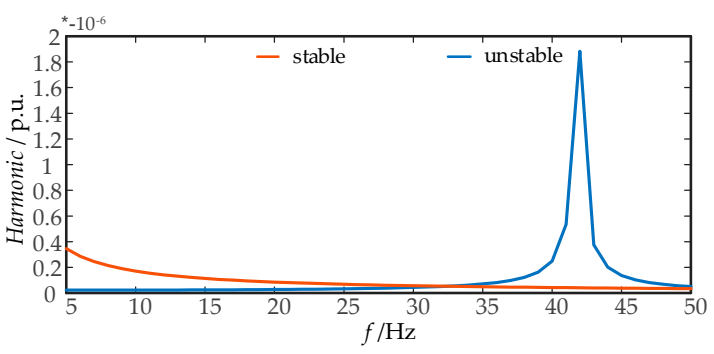

(b)

Figure 13. The electrical damping coefficient $D_{\mathrm{e}}$ and the inter-harmonic distribution in case 1 (a) The electrical damping coefficient $D_{\mathrm{e}}$; (b) The inter-harmonic distribution. 


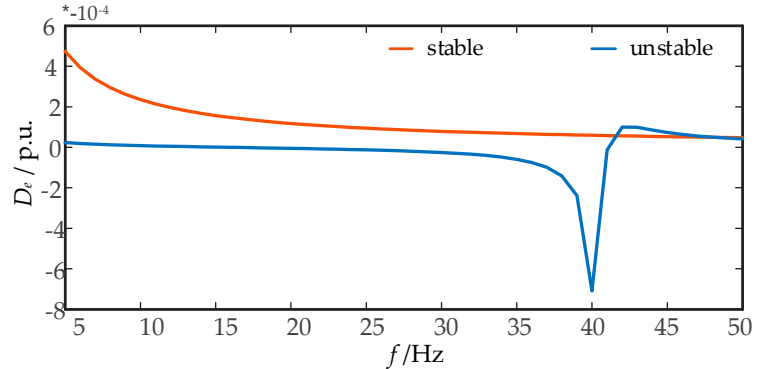

(a)

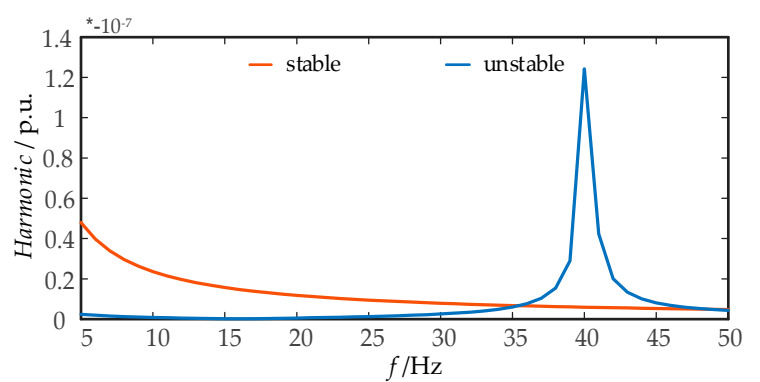

(b)

Figure 14. The electrical damping coefficient $D_{\mathrm{e}}$ and the inter-harmonic distribution in case 2 (a) The electrical damping coefficient $D_{\mathrm{e}}$; (b) The inter-harmonic distribution.

According to Figures 13 and 14, it can be seen that: under the condition of case 1, when the system is stable, the electromagnetic damping coefficient $D_{\mathrm{e}}$ of DFIG turbine is always positive and there is no harmonic; when the system is unstable, the oscillation frequency is about $42 \mathrm{~Hz}$ in case 1 ( $40 \mathrm{~Hz}$ in case 2) which is consistent with the result of eigenvalue analysis. When $f=42 \mathrm{~Hz}$ in case $1(40 \mathrm{~Hz}$ in case 2), the electromagnetic damping coefficient $D_{\mathrm{e}}$ of DFIG turbine becomes negative, which leads to oscillation instability of the system.

\section{Conclusions}

Based on the principle that the similarity matrix has the same eigenvalues, the equivalence of DFIG wind farm connected with the series compensated transmission network has been studied and the equivalence process has a strict theoretical basis. Then, through the eigenvalue analysis method, the effectiveness of DFIG wind farm's equivalent model is analyzed considering the differences in the number of DFIG turbines and the collection lines. Finally, a simulation model is built in EMTDC/PSCAD, through the online damping analysis method, the equivalent model's effectiveness is further verified and the oscillation mechanism is further revealed. The results show that:

The same parallel DFIG wind turbines connected with series compensated transmission network can be characterized by two separate units. One unit can reflect the oscillation model between DFIG turbines and the other one can reflect the oscillation model between DFIG turbines and grid. As for DFIG wind turbines which do not meet the equivalence conditions, based on the similarity of operational conditions. Thence, DFIG wind farm is divided into groups and each group can be equivalent to two separate units, while different groups cannot be equivalent.

The equivalent model can accurately reflect the dominant oscillation characteristics of DFIG wind farm. The average Euclidean distance of dominant eigenvalues is about $0.02 \sim 0.03$. When considering the difference between the number of DFIG turbines and the collector lines, the accuracy of the equivalent model is basically unchanged. In addition, the equivalent model can reflect the super-synchronous oscillation characteristics.

Based on the online damping analysis method, the mechanism of SSR in DFIG wind farm connected with series compensated transmission network is explained. When the system oscillates, the electromagnetic damping coefficient of DFIG turbines are negative. Under the oscillation frequency, the system damping becomes smaller which leads the system unstable.

Author Contributions: Conceptualization, G.Y. and Q.J.; methodology, Q.J.; software, D.W.; validation, D.W. and W.H.; formal analysis, G.Y. and Q.J.; investigation, D.W. and W.H.; resources, G.Y.; data curation, D.W.; writing — original draft preparation, D.W.; writing—review and editing, D.W.; visualization, Q.J.; supervision, G.Y.; project administration, G.Y.; funding acquisition, G.Y. All authors have read and agreed to the published version of the manuscript.

Funding: This research was funded by National Natural Science Foundation of China, grant number U1866601.

Conflicts of Interest: The authors declare no conflict of interest. 


\section{Appendix A}

Table A1. Parameter of DFIG.

\begin{tabular}{cc}
\hline & List of Notations \\
\hline$\psi_{\mathrm{sdq}}$ & the flux linkage of stator \\
$\psi_{\mathrm{rdq}}$ & the flux linkage of rotor \\
$\omega_{\mathrm{r}}$ & actual value rotor speed \\
$\omega_{\mathrm{rref}}$ & reference value of rotor speed \\
$T_{m}$ & mechanical torque \\
$Q_{\mathrm{s}}$ & actual value of the stator reactive power \\
$Q_{\mathrm{sref}}$ & reference value of the stator reactive power \\
$i_{\mathrm{cg}}$ & output current of GSC \\
$i_{\mathrm{r}}$ & output current of RSC \\
$i_{\mathrm{g}}$ & the transmission line current \\
$u_{\mathrm{dc}}$ & actual value of voltage in dc link \\
$u_{\mathrm{dcref}}$ & reference value of voltage in dc link \\
$u_{\mathrm{s}}$ & voltage of stator \\
$u_{\mathrm{r}}$ & output voltage of RSC \\
$u_{\mathrm{cg}}$ & output voltage of GSC \\
$u_{\mathrm{t}}$ & actual voltage of PCC \\
$u_{\mathrm{tref}}$ & reference voltage of PCC \\
$u_{\mathrm{c}}$ & the ground capacitance voltage \\
$u_{\mathrm{css}}$ & State variables in the control \\
$x_{1} \sim \Delta x_{8}$ &
\end{tabular}

Table A2. Notations of Matrix.

\begin{tabular}{cc}
\hline & List of Notations \\
\hline $\mathrm{A}_{\mathrm{U}}$ & coupling relationship between state variables of DFIG \\
$\mathrm{A}_{\mathrm{L}}$ & coupling relationship between state variables of grid \\
$\mathrm{B}_{\mathrm{U}}$ & relationship of voltage between DFIG and grid \\
$\mathrm{B}_{\mathrm{I}}$ & relationship of current between DFIG and grid \\
$X_{\mathrm{U} 1}$ & state variables of DFIG turbine 1 \\
$X_{\mathrm{U} 2}$ & state variables of DFIG turbine 2 \\
$X_{\mathrm{L}}$ & state variables of grid \\
$\mathrm{A}$ & state matrix of 2-mechines system \\
$\mathrm{P}$ & similar transformation matrix of $\mathrm{A}$ \\
$\mathrm{B}$ & similarity matrix of A \\
$\mathrm{A}_{\mathrm{N}}$ & state matrix of $n$-machine system \\
$\mathrm{B}_{\mathrm{N}}$ & similarity matrix of $\mathrm{A}_{\mathrm{N}}$ \\
\hline
\end{tabular}

\section{Appendix B}

Table A3. The input wind speed of DFIG wind farm in $t_{1}$.

\begin{tabular}{cccc}
\hline Number & Operating Condition $(\mathbf{m} / \mathbf{s})$ & Number & Operating Condition $(\mathbf{m} / \mathbf{s})$ \\
\hline 1 & 5.923 & 11 & 4.292 \\
2 & 6.742 & 12 & 4.133 \\
3 & 5.205 & 13 & 4.046 \\
4 & 5.118 & 14 & 3.625 \\
5 & 5.082 & 15 & 3.466 \\
6 & 5.655 & 16 & 3.843 \\
7 & 5.669 & 17 & 3.770 \\
8 & 6.249 & 18 & 5.133 \\
9 & 6.655 & 19 & 3.756 \\
10 & 6.923 & 20 & 4.625 \\
\hline
\end{tabular}


Table A4. The input wind speed of DFIG wind farm in $t_{2}$.

\begin{tabular}{cccc}
\hline Number & Operating Condition $(\mathbf{m} / \mathbf{s})$ & Number & Operating Condition $(\mathbf{m} / \mathbf{s})$ \\
\hline 1 & 4.611 & 11 & 4.727 \\
2 & 6.162 & 12 & 4.785 \\
3 & 5.118 & 13 & 4.596 \\
4 & 4.335 & 14 & 5.582 \\
5 & 4.357 & 15 & 3.93 \\
6 & 4.335 & 16 & 4.364 \\
7 & 5.698 & 17 & 4.698 \\
8 & 5.249 & 18 & 4.77 \\
9 & 5.684 & 19 & 4.292 \\
10 & 6.119 & 20 & 4.002 \\
\hline
\end{tabular}

Table A5. The results of grouping in $t_{2}$.

\begin{tabular}{cccc}
\hline Groups & Operating Condition $(\mathrm{m} / \mathbf{s})$ & Sub-Groups & Operating Condition $(\mathrm{m} / \mathbf{s})$ \\
\hline Group 1 & 3.93 & & 4.727 \\
& 4.002 & & 4.77 \\
4.292 & Group 3 & 4.785 \\
4.335 & & 5.118 \\
& 4.335 & Group 4 & 5.249 \\
& 4.357 & & 5.692 \\
& 4.364 & & 5.684 \\
Group 2 & 4.596 & Group 5 & 5.582 \\
& 4.611 & & 6.119 \\
& 4.698 & & 6.162 \\
\hline
\end{tabular}

Table A6. The partial eigenvalues of detailed model and equivalent model.

\begin{tabular}{|c|c|c|}
\hline Detailed Model & Single-Machine to Infinite Bus System & Modified Single-Machine to Grid System \\
\hline-5020 & -4960 & \\
\hline-4740 & -4740 & -4740 \\
\hline-4620 & -4620 & -4620 \\
\hline-4530 & -4590 & \\
\hline$-4010 \pm j 17,400$ & $-4000 \pm j 17,400$ & \\
\hline$-1570 \pm j 15,800$ & $-1590 \pm j 15,800$ & \\
\hline-111 & -111 & -111 \\
\hline-93 & -92.6 & \\
\hline-30.7 & -30.7 & -30.7 \\
\hline-30.6 & & -30.6 \\
\hline-30.2 & -30.3 & \\
\hline-29.5 & -29.4 & \\
\hline-29 & & -29.1 \\
\hline-28.2 & -28.2 & \\
\hline-27.9 & & -27.9 \\
\hline-20.1 & -20.1 & -20.1 \\
\hline-20 & -20 & -20 \\
\hline$-16 \pm j 22.2$ & $-16 \pm j 22.2$ & \\
\hline$-16 \pm j 22$ & & $-16 \pm j 22$ \\
\hline$-15.8 \pm j 23.4$ & $-15.8 \pm j 23.1$ & $-15.8 \pm j 23.3$ \\
\hline$-15.3 \pm j 25.6$ & & $-15.4 \pm j 25.9$ \\
\hline$-15.3 \pm j 24.8$ & $-15.3 \pm j 24.9$ & \\
\hline$-14.8 \pm j 28.3$ & $-14.8 \pm j 27.8$ & $-14.9 \pm j 28.5$ \\
\hline-14.7 & -14.7 & \\
\hline-11.9 & -11.9 & \\
\hline-11 & -11 & -11 \\
\hline
\end{tabular}


Table A6. Cont.

\begin{tabular}{ccc}
\hline Detailed Model & Single-Machine to Infinite Bus System & Modified Single-Machine to Grid System \\
\hline$-10.4 \pm j 313$ & $-10.1 \pm j 313$ & $-10.4 \pm j 313$ \\
$-10.1 \pm j 313$ & $-9.1 \pm j 313$ & $-9.36 \pm j 313$ \\
$-9.32 \pm j 313$ & $-8.92 \pm j 23.1$ & \\
$-9.07 \pm j 313$ & & \\
$-8.96 \pm j 23$ & $-8.35 \pm j 313$ & $-8.4 \pm j 313$ \\
$-8.5 \pm j 313$ & $-8.06 \pm j 313$ & $-8.06 \pm 313$ \\
$-8.25 \pm j 313$ & $-7.62 \pm j 370$ & \\
$-8.06 \pm j 313$ & -4.2 & \\
$-7.62 \pm j 370$ & $-3.3 \pm j 3.03$ & $-3.18 \pm j 3.03$ \\
-4.21 & & \\
$-3.31 \pm j 3.04$ & $-3.16 \pm j 3.03$ & $-3.07 \pm j 3.02$ \\
$-3.18 \pm j 3.03$ & $-3.06 \pm j 3.02$ & $-3.03 \pm j 3.02$ \\
$-3.15 \pm j 3.03$ & $-3.03 \pm j 3.02$ & \\
$-3.08 \pm j 3.02$ & $-2.62 \pm j 3.85$ & $-1.32 \pm j 1.50$ \\
$-3.03 \pm j 3.02$ & $-2.45 \pm j 259$ & $-1.31 \pm j 1.46$ \\
$-2.63 \pm j 3.84$ & $-1.32 \pm j 1.50$ & \\
$-2.46 \pm j 259$ & $-1.31 \pm j 1.46$ & \\
$-1.32 \pm j 1.50$ & & \\
$-1.31 \pm j 1.46$ & &
\end{tabular}

Table A7. Parameter of DFIG.

\begin{tabular}{cc}
\hline Parameter & Unit/p.u. \\
\hline Stator resistance $r_{\mathrm{s}}$ & 0.0164 \\
Stator leakage reactance $X_{\mathrm{S}}$ & 0.255 \\
Rotor resistance $r_{\mathrm{r}}$ & 0.0183 \\
Rotor leakage reactance $X_{\mathrm{r}}$ & 0.222 \\
Excitation reactance $X_{\mathrm{m}}$ & 13.68 \\
\hline
\end{tabular}

\section{References}

1. China National Energy Administration, Operation of Wind Farm in First Half of 2019. Available online: http://www.nea.gov.cn/2019-07/26/c_138259422.htm (accessed on 26 July 2019).

2. Yuan, X.; Cheng, S.; Hu, J. Multi-time Scale Voltage and Power Angle Dynamics in Power Electronics Dominated Large Power Systems. Proc. CSEE 2016, 36, 5145-5154.

3. Mohammadpour, H.A.; Santi, E. SSR Damping Controller Design and Optimal Placement in Rotor-Side and Grid-Side Converters of Series-Compensated DFIG-Based Wind Farm. IEEE Trans. Sustain. Energy 2015, 6, 388-399. [CrossRef]

4. Fan, L.; Miao, Z. Wind in Weak Grids: $4 \mathrm{~Hz}$ or $30 \mathrm{~Hz}$ Oscillations? IEEE Trans. Power Syst. 2018, 23, 5803-5804. [CrossRef]

5. Adams, J.; Carter, C.; Huang, S.H. ERCOT Experience with Sub-synchronous Control Interaction and Proposed Remediation. In Proceedings of the Transmission \& Distribution Conference \& Exposition, Orlando, FL, USA, 8-10 May 2012; pp. 1-5.

6. Dong, X.; Tian, X.; Zhang, Y. Practical SSR Incidence and Influencing Factor Analysis of DFIG-based Series-compensated Transmission System in Guyuan Farms. High Volt. Eng. 2017, 43, 327-334.

7. Fan, L.; Kavasseri, R.; Miao, Z. Modeling of DFIG-Based Wind Farms for SSR Analysis. IEEE Trans. Power Deliv. 2010, 25, 2073-2082. [CrossRef]

8. Wang, L.; Xie, X.; Jiang, Q. Analysis and Mitigation of SSR Problems in Large-scale Wind Farms with Doubly-fed Wind Turbines. Autom. Electr. Power Syst. 2014, 38, 26-31.

9. Li, R.; Lu, Y.; Liu, H. Mechanism Analysis on Subsynchronous Oscillation Caused by Grid-integration of Doubly-fed Wind Power Generation System via Series Compensation. Power Syst. Technol. 2013, 37, 3073-3079.

10. Fan, L.; Miao, Z. Nyquist-Stability-Criterion-Based SSR Explanation for Type-3 Wind Generators. IEEE Trans. Energy Convers. 2012, 27, 807-809. [CrossRef] 
11. Xie, X.; Zhang, X.; Liu, H.; Li, Y.; Zhang, C. Characteristic Analysis of Subsynchronous Resonance in Practical Wind Farms Connected to Series-Compensated Transmissions. IEEE Trans. Energy Convers. 2017, 32, 1117-1126. [CrossRef]

12. Du, W.; Ren, B.; Wang, H. Comparison of Methods to Examine Sub-Synchronous Oscillations Caused by Grid-Connected Wind Turbine Generators. IEEE Trans. Power Syst. 2019, 34, 4931-4943. [CrossRef]

13. Zhan, Y.; Xie, X.; Liu, H. Frequency-Domain Modal Analysis of the Oscillatory Stability of Power Systems with High-Penetration Renewables. IEEE Trans. Sustain. Energy 2019, 10, 1534-1543. [CrossRef]

14. Fan, L.; Zhu, C.; Miao, Z. Modal Analysis of a DFIG-Based Wind Farm Interfaced with a Series Compensated Network. IEEE Trans. Energy Convers. 2011, 26, 1010-1020. [CrossRef]

15. Dong, X.; Xie, X.; Yang, Y. Impacting Factors and Stable Area Analysis of Subsynchronous Resonance in DFIG Based Wind Farms Connected to Series-Compensated Power System. Power Syst. Technol. 2015, 39, 189-193.

16. Dong, X.; Xie, X.; Li, J. Comparative Study of the Impact on Sub-synchronous Resonance Characteristics from the Different Location of Wind Generators in a Large Wind Farm. Proc. CSEE 2015, 35, 5173-5180.

17. Mi, Z.; Wang, Y. Applicability and Improvement of Common-Used Equivalent Methods for Wind Farms. Power Syst. Technol. 2010, 34, 175-180.

18. Huang, P.H.; El Moursi, M.S.; Xiao, W. Subsynchronous Resonance Mitigation for Series-Compensated DFIG-Based Wind Farm by Using Two-Degree-of-Freedom Control Strategy. IEEE Trans. Power Syst. 2015, 30, 1442-1454. [CrossRef]

19. Suvire, G.O.; Mercado, P.E. Wind farm: Dynamic model and impact on a weak power system. In Proceedings of the Transmission \& Distribution Conference \& Exposition: Latin America, Bogota, Columbia, 13-15 August 2008.

20. Chen, J.; Wang, H.; Zhang, Z. Research on Equivalent Accuracy of Wind Farm Composed of DFIG wind farm. Power Syst. Technol. 2014, 38, 1867-1872.

21. An, Z.; Shen, C.; Zheng, Z. Assessment Method for Equivalent Models of Wind Farms Based on Direct-Driven Wind Generators Considering Randomness. Proc. Chin. Soc. Electr. Eng. 2018, 38, 6511-6519.

22. Faried, S.O.; Unal, I.; Rai, D. Utilizing DFIG-Based Wind Farms for Damping Sub-synchronous Resonance in Nearby Turbine-Generators. IEEE Trans. Power Syst. 2013, 28, 452-459. [CrossRef]

23. Yang, F.; Wang, X.; Xu, Y. Equivalent Simplification of Torsional Interaction in Identical Multi-machine Power Systems. Proc. Chin. Soc. Electr. Eng. 2006, 26, 6-11.

24. Wu, H.; He, Y.; Zhao, B. Research on Dynamic Equivalent of Wind Fram Based on Improved K-means Clustering Algorithm. Acta Energ. Sol. Sin. 2018, 39, 3232-3238.

25. Wang, P.; Zhang, Z.; Huang, Q. Improved Wind Farm Aggregated Modeling Method for Large-scale Power System Stability Studies. IEEE Trans. Power Syst. 2018, 33, 6332-6342. [CrossRef]

26. Yogarathinam, A.; Kaur, J.; Chaudhuri, N.R. Impact of Inertia and Effective Short Circuit Ratio on Control of Frequency in Weak Grids Interfacing LCC-HVDC and DFIG-Based Wind Farms. IEEE Trans. Power Deliv. 2017, 32, 2040-2051. [CrossRef]

Publisher's Note: MDPI stays neutral with regard to jurisdictional claims in published maps and institutional affiliations.

(C) 2020 by the authors. Licensee MDPI, Basel, Switzerland. This article is an open access article distributed under the terms and conditions of the Creative Commons Attribution (CC BY) license (http://creativecommons.org/licenses/by/4.0/). 